\title{
Bacillus cereus AR156 Activates Defense Responses to Pseudomonas syringae pv. tomato in Arabidopsis thaliana Similarly to flg22
}

\author{
Shune Wang, ${ }^{1,2}$ Ying Zheng, ${ }^{1,2}$ Chun Gu, ${ }^{3}$ Chan He, ${ }^{1,2}$ Mengying Yang, ${ }^{1,2}$ Xin Zhang, ${ }^{1,2}$ Jianhua Guo,,${ }^{1,2}$ \\ Hongwei Zhao, ${ }^{1,2}$ and Dongdong Niu ${ }^{1,2,+}$ \\ ${ }^{1}$ College of Plant Protection, Nanjing Agricultural University, Nanjing 210095, China; ${ }^{2}$ Key Laboratory of Integrated Management \\ of Crop Diseases and Pests (Nanjing Agricultural University), Ministry of Education; and ${ }^{3}$ Jiangsu Provincial Anfeng Biogenic \\ Pesticide Engineering Center Co., Ltd., Taicang 215400, China
}

Accepted 30 October 2017.

\begin{abstract}
Bacillus cereus AR156 (AR156) is a plant growth-promoting rhizobacterium capable of inducing systemic resistance to Pseudomonas syringae pv. tomato in Arabidopsis thaliana. Here, we show that, when applied to Arabidopsis leaves, AR156 acted similarly to flg22, a typical pathogen-associated molecular pattern (PAMP), in initiating PAMP-triggered immunity (PTI). AR156elicited PTI responses included phosphorylation of MPK3 and MPK6, induction of the expression of defense-related genes $P R 1, F R K 1, W R K Y 22$, and WRKY29, production of reactive oxygen species, and callose deposition. Pretreatment with AR156 still significantly reduced $P$. syringae pv. tomato multiplication and disease severity in NahG transgenic plants and mutants sid2-2, jar1, etr1, ein2, npr1, and fls2. This suggests that AR156induced PTI responses require neither salicylic acid, jasmonic acid, and ethylene signaling nor flagella receptor kinase FLS2, the receptor of flg22. On the other hand, AR156 and flg22 acted in concert to differentially regulate a number of AGO1-bound microRNAs that function to mediate PTI. A full-genome transcriptional profiling analysis indicated that AR156 and flg22 activated similar transcriptional programs, coregulating the expression of 117 genes; their concerted regulation of 16 genes was confirmed by real-time quantitative polymerase chain reaction analysis. These results suggest that AR156 activates basal defense responses to $P$. syringae pv. tomato in Arabidopsis, similarly to flg22.
\end{abstract}

To defend themselves against pathogens, plants have evolved multiple layers of defense mechanisms to protect themselves from pathogen infection (Jones and Takemoto 2004). The first layer is comprised of the plant surface-localized receptors termed pattern-recognition receptors (PRRs) that perceive pathogen- or microbe-associated molecular patterns (PAMPs or MAMPs), consisting of lipopolysaccharide (Dow et al. 2000), glycoprotein, peptide, and polysaccharide (Kaku et al. 2006; Zipfel and Felix 2005). Well-studied PAMPs include flg22, a peptide comprising 22 amino acids of the highly conserved elicitor-active epitope of flagellin (Felix et al. 1999). Recognition of PAMPs by PRRs initiates PAMP-triggered immunity (PTI), which involves a

\section{${ }^{\dagger}$ Corresponding author: Dongdong Niu; E-mail: ddniu@njau.edu.cn}

*The $\boldsymbol{e}$-Xtra logo stands for "electronic extra" and indicates that one supplementary figure and four supplementary tables are published online.

C 2018 The American Phytopathological Society variety of defense responses including activation of mitogenactivated protein kinases (MAPKs), oxidative burst, callose deposition, and defense-related gene expression. On the other hand, to successfully infect plants, pathogens suppress PTI by delivering specific virulence proteins generically termed effectors into the plant cell (Altenbach and Robatzek 2007; Thomma et al. 2011). In response to effectors, some plants have evolved resistance proteins to recognize specific pathogen effectors, thereby eliciting effector-triggered immunity (ETI), usually accompanied by a hypersensitive response at the infection site (Chisholm et al. 2006; Jones and Dangl 2006) to restrict biotrophic pathogen growth.

The typical PAMP flg22 induces PTI in wild-type plants but not in plants carrying mutations in the gene encoding flagellin sensing 2 (FLS2), a leucine-rich repeat (LRR)-type receptor kinase required for flagellin binding and signaling (GómezGómez et al. 2001). FLS2 forms a complex with flg22 and brassinosteroid-associated kinase 1 (BAK1), therefore activating downstream defense-signaling pathways (Sun et al. 2013), which leads to MAPK activation, a transient oxidative burst (reactive oxygen species [ROS]) (Felix et al. 1999), callose ( $\beta$-1,3-glucan) deposition at the cell walls (Brown et al. 1998; Kim et al. 2005), and the expression of defense-related genes (Gravino et al. 2015; Zipfel et al. 2004).

To survive pathogen attack, plants possess distinct defense signaling pathways, which can interact antagonistically, synergistically, or in parallel, depending on the type of pathogen encountered, resulting in optimization of the specificity of plant defense responses. One of the best-studied examples of defense signaling pathway crosstalk is the antagonistic interaction between the salicylic acid (SA) and the jasmonic acid-ethylene (JA/ET) response pathways (Kazan and Manners 2008; Koornneef and Pieterse 2008; Pieterse et al. 2012). Flg22-induced resistance appears to be independent of SA, JA, and ET signaling pathways in the analysis of the pathways in parallel, so knocking out a single pathway alone does not abolish the induction of resistance. A recent study showed that flg22-triggered oxidative burst and callose deposition are regulated positively by the SA pathway and negatively by the JA pathway (Yi et al. 2014). JA signaling can be activated by coronatine (COR), a structural mimic of JA-isoleucine produced by Pseudomonas syringae pv. tomato, which is antagonistic to activated SA signaling, thus suppressing flg22-triggered oxidative burst; hence, COR-mediated suppression of flg22-triggered oxidative burst involves the mechanism of JA-SA antagonism (Yi et al. 2014).

Small RNAs (sRNAs) are key regulators of plant defense responses against bacterial infection (Niu et al. 2015). microRNAs 
(miRNAs), a class of noncoding sRNAs of 21 to 24 nucleic acids, regulate defense-related gene expression through miRNAmediated gene silencing pathways. miR393 is the first sRNA found to participate in PTI, which can be induced by flg22 and positively regulates PTI by suppressing auxin signaling through downregulation of the gene expression of the F-box auxin receptors TIR1, AFB2, and AFB3 (Navarro et al. 2006). In addition, miR160a, miR398b, and miR773 are involved in the regulation of callose deposition, thus acting in PTI signaling ( $\mathrm{Li}$ et al. 2010). miR393b* facilitates exocytosis of an antimicrobial pathogenesis-related (PR) protein by targeting a Golgi-localized SNARE gene, thereby functioning in ETI signaling (Zhang et al. 2011). Moreover, some miRNAs have been shown to guide the regulation of disease resistance genes ( $\mathrm{Li}$ et al. 2012; Niu et al. 2016b; Zhai et al. 2011). On the other hand, argonaute (AGO) proteins are the core molecules of the effector complex in SRNAdirected gene silencing, which is a widespread mechanism of gene regulation. For example, AGO1 is primarily associated with miRNAs and plays an important role in flg22-induced resistance to bacteria ( $\mathrm{Li}$ et al. 2010), and AGO2 is strongly induced in Arabidopsis upon infection with avirulent $P$. syringae pv. tomato (avrRpt2) strains and is indispensable to antibacterial immune responses (Zhang et al. 2011).

In our previous study (Niu et al. 2011), pretreatment of wildtype Arabidopsis Col-0 roots with Bacillus cereus AR156 induced systemic resistance (ISR) in Arabidopsis thaliana by simultaneously activating salicylate- and jasmonate/ET-dependent signaling pathways. Recently, we found that leaf infiltration of AR156 induced systemic acquired resistance (SAR) in systemic leaves of Arabidopsis through a NPR1- and SA-dependent signaling pathway but independently of JA and ET signaling pathways (Niu et al. 2016a). We also showed that pretreatment with AR156 primed ISR to $P$. syringae pv. tomato infection by suppressing miR825 and miR825* and activating the defense-related target genes (Niu et al. 2016b). Interestingly, pretreatment with AR156 drastically reduced the abundance of miR398b and miR773 (Niu et al. 2016b), as did flg22 (Li et al. 2010). This phenomenon inspired us to investigate whether AR156 shares the same function of flg22 in triggering PTI, given that miR398b and miR773 are negative regulators of PTI against bacterial pathogens (Li et al. 2010). Our results indicated that AR156 functioned similarly to flg22 in inducing basal defense responses in Arabidopsis, which involve PTI response and miRNA-mediated gene expression. Furthermore, a transcriptional profiling analysis revealed that 117 genes were differentially regulated by both AR156 and flg22, indicating that they elicited highly correlated transcriptional responses.

\section{RESULTS}

AR156 induces plant resistance to $P$. syringae pv. tomato.

We previously demonstrated that AR156, applied as leaf infiltration, triggered SAR by priming systemic leaves to activate multiple PTI components (Niu et al. 2016a). In this study, we performed infection assays to investigate whether it shares the function of flg22 to confer local resistance to $P$. syringae pv. tomato in the pretreated leaves. Leaves of wild-type Arabidopsis Col-0 plants were syringe-infiltrated with either AR156 or flg22 1 day before challenge-inoculation with $P$. syringae pv. tomato. Compared with the nontreated control, both AR156 and flg22 treatments reduced the disease symptoms on leaves at 2 days post-treatment (dpt) (Fig. 1A). In agreement with the reduction in disease symptoms observed on the leaf surface, $P$. syringae pv. tomato population density also significantly declined by about 100 -fold in leaves pretreated with AR156 or flg22 at 2 dpt relative to that in control leaves (Fig. 1B), signifying that AR156 conferred effective local resistance against $P$. syringae pv. tomato infection in the pretreated leaves, as did flg22. On the other hand, the lower $P$. syringae pv. tomato densities observed in AR156 treatment may be due, in part, to niche-occupation by AR156.

\section{AR156 elicits PTI defense responses.}

To investigate the mechanisms underlying AR156-induced antibacterial resistance, we determined the effect of AR156 on several PTI components in wild-type Arabidopsis Col-0 leaves. Callose deposition and $\mathrm{H}_{2} \mathrm{O}_{2}$ accumulation were noticeable at $24 \mathrm{~h}$ post-treatment (hpt) in leaves infiltrated with AR156 or flg22 but were absent in control leaves (Fig. 2A). Consistently, in the PRI::GUS transgenic Arabidopsis plants with PRI promoter fused to a $G U S$ ( $\beta$-glucuronidase) reporter, PR1 protein was expressed in the leaves infiltrated with AR156 or flg22, as manifested by the precipitate indicating GUS activity, but was absent in control leaves (Fig. 2A).

We also examined whether AR156 can trigger MAPK activation, an early event in PTI signaling. As a result, phosphorylated MPK3 and MPK6 were first detected in the leaves at 15 minutes post-treatment (mpt) with AR156 applied as a foliar spray, while treatment with flg22 induced their phosphorylation as early as $5 \mathrm{mpt}$, remaining robust until $30 \mathrm{mpt}$ (Fig. 2B). This indicates that AR156 treatment triggers MAPK activation less strongly than flg22 treatment.

We also determined the expression patterns of the PAMPresponse genes FRK1 (encoding flg22-induced receptor-like kinase 1), $W R K Y 22$, and $W R K Y 29$ (Asai et al. 2002) in wild-type

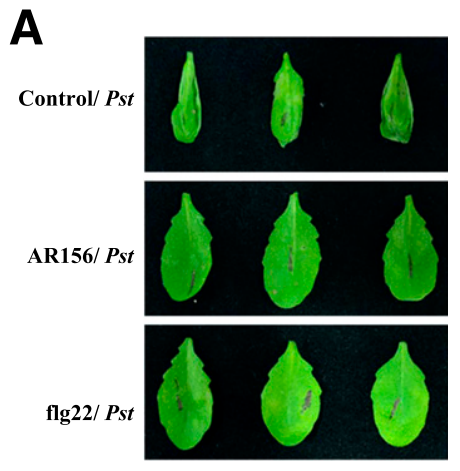

B

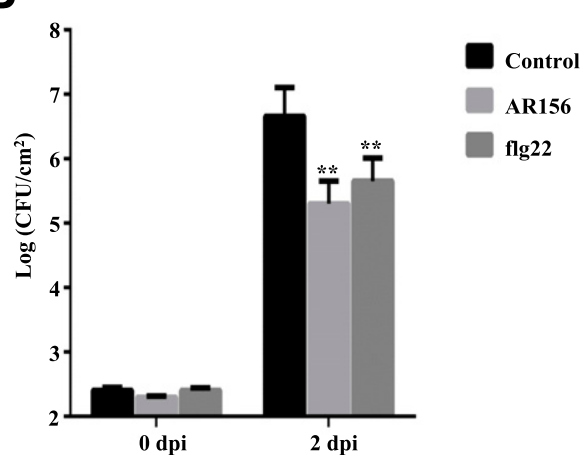

Fig. 1. Bacillus cereus AR156 conferred resistance to Pseudomonas syringae pv. tomato (Pst) in Arabidopsis. A, Images of Arabidopsis Col-0 leaves with disease symptoms at 2 days postinoculation (dpi) with $P$. syringae pv. tomato $\left(5 \times 10^{5} \mathrm{CFU} / \mathrm{ml}\right)$. Leaves were syringe-infiltrated with $\mathrm{AR} 156 \mathrm{at} 5 \times 10^{7} \mathrm{CFU} / \mathrm{ml}$, $1 \mu \mathrm{M}$ flg22, or water at $24 \mathrm{~h}$ before P. syringae pv. tomato infection. B, Bacterial population density in leaves was measured at $2 \mathrm{dpi}$. Student's $t$ test was carried out to determine the significance of the differences between treatment AR156 or flg22 and the control. Asterisks (**) indicate significant differences at a $P$ value $<0.01$. The data shown are means \pm standard deviation $(n=12)$ from one representative experiment among three independent repetitions. 
Col-0 plants treated with AR156 or flg22, using quantitative reverse transcription-polymerase chain reaction (qRT-PCR). Both treatments substantially enhanced the accumulation of FRK1 transcript at $30 \mathrm{mpt}$, and the transcript levels of WRKY22 and WRKY29 increased in seedlings at $10 \mathrm{mpt}$ (Fig. 2C). Collectively, the above results revealed striking parallels between AR156 and flg22 in their function to induce PTI responses and defense-related gene expression.

\section{AR156-induced resistance to $P$. syringae pv. tomato requires AGO1 and DCL but \\ neither FLS2 nor SA-, JA-, and ET-pathways.}

To further clarify the molecular mechanisms by which AR156 induces plant resistance to $P$. syringae pv. tomato, we carried out infection assays using wild-type Col-0, NahG transgenic plants, mutants with impaired SA-, JA-, or ET-signaling pathway (jarl, etr 1 , ein2, sid2-2, nprl), and the transgenic line NahG. Two-way analysis of variance (ANOVA) with Tukey's test was used to compare the levels of AR156- and flg22-induced resistance to P. syringae pv. tomato in these plants. Pretreatment with AR156 or flg22 significantly reduced disease symptoms (Fig. 3A) and P. syringae pv. tomato population densities in leaves (Fig. 3B) of wild-type plants as well as all mutants. On the other hand, $P$. syringae pv. tomato population densities were significantly higher in sid2-2, nprl, and NahG plants than in Col-0 in both AR156 and flg22 treatments; meanwhile, this parameter was also significantly higher in sid2-2, nprl, and NahG plants than in Col-0 in the control group. The two-way ANOVA revealed that the interaction between treatment (AR156, flg22, or the control) and genotype was not statistically significant and that the overall levels of AR156- and flg22-induced resistance to $P$. syringae pv. tomato were not significantly different. Taken together, these results demonstrate that SA-, JA-, and ETmediated signaling pathways are not essential for AR156-induced basal defense responses to $P$. syringae pv. tomato.

Acting as the receptor of flg22, FLS2 is essential for flg22induced resistance to $P$. syringae pv. tomato. To determine whether FLS2 is also required for AR156-induced PTI responses to $P$. syringae pv. tomato, we assessed the effect of AR156 pretreatment on fls 2 plants. Consequently, the disease symptoms were significantly attenuated by AR156 at 2 days postinoculation (dpi) but not by flg22 in fls 2 plants in which AR156 pretreatment also significantly reduced bacterial proliferation relative to the control (Fig. 3C and D). This pointed to the fact that AR156induced resistance does not require a functional FLS2.

Previous studies showed that miRNAs function to regulate plant resistance to bacterial pathogens ( $\mathrm{Li}$ et al. 2010; Navarro et al. 2006; Niu et al. 2016b; Zhang et al. 2011). As the key
A

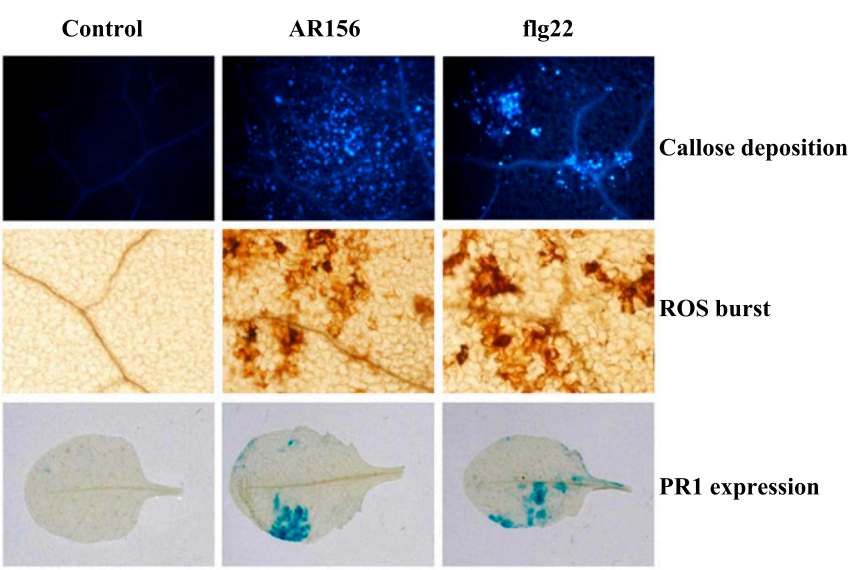

B

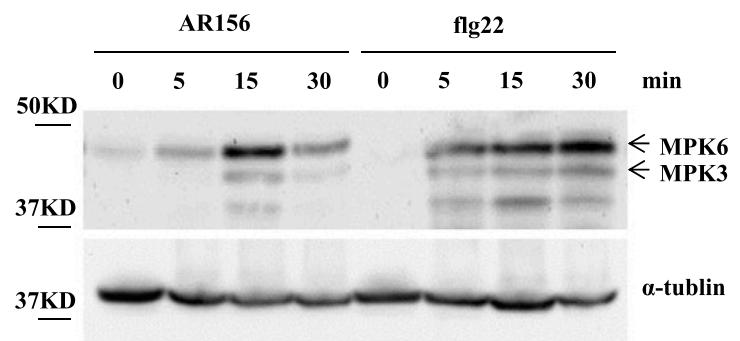

C

aR156 $=$ flg22
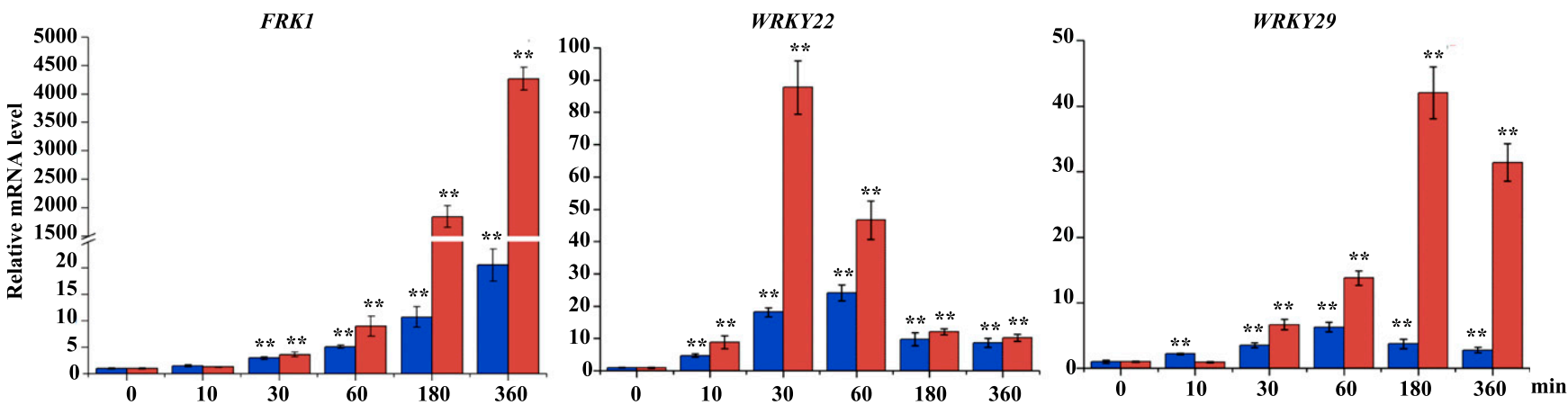

Fig. 2. AR156 activated defense responses and pathogen-associated molecular pattern-triggered immunity components. A, AR156- and flg22-induced callose deposition, reactive oxygen species burst, and PR1 expression in Arabidopsis Col-0 and transgenic PR1::GUS leaves. Plants were infiltrated with $5 \times 10^{7}$ CFU of AR156 per milliliter, $1 \mu \mathrm{M}$ flg22, or water. Samples were collected at $24 \mathrm{~h}$ post-treatment. B, AR156- and flg22-induced activation of mitogen-activated protein kinases in Col-0. Two-week-old seedlings grown on Murashige and Skoog (MS) medium were sprayed with $5 \times 10^{8}$ CFU of AR156 per milliliter or $10 \mu \mathrm{M}$ flg22. Samples were collected at 0, 5, 15, and $30 \mathrm{~min}$. C, Quantitative reverse transcription-polymerase chain reaction analysis of AR156- and flg22induced expression of FRK1, WRKY22, and WRKY29 in Col-0. Plants grown on MS medium for two weeks were sprayed with $5 \times 10^{8} \mathrm{CFU}$ of AR156 per milliliter or $10 \mu \mathrm{M}$ flg22. Samples were collected at 0, 30, 60, 120, 240, and $360 \mathrm{~min}$. The data are shown as means \pm standard deviation from three technical replicates. Similar results were obtained in three biological replicates. Student's $t$ test was performed to determine the significance of the differences between treatment with AR156 and flg22. Asterisks (* and $* *$ ) indicate significant differences at $P$ values $<0.05$ and $<0.01$, respectively. 
components of miRNAs biogenesis, both AGO1 and Dicerlike (DCL) proteins play an important regulatory role in flg22induced antibacterial resistance ( $\mathrm{Li}$ et al. 2010). Recently, we uncovered overlap between AR156- and flg22-mediated miRNAs (Li et al. 2010; Niu et al. 2016b). Thus, in this study, we carried out infection assays using agol-27 and dcll-9 mutants to clarify the role of AGO1 and DCL in AR156-induced resistance to $P$. syringae pv. tomato. At $2 \mathrm{dpi}$, both treatments AR156 and flg22 caused a significant reduction in disease severity in wild-type Col-0 and Ler plants but not in agol-27 and dcll-9 mutants. In agreement with the differences in disease severity between wild-type plants and mutants, bacterial population size significantly decreased by approximately 100 -fold in wild-type Col-0 and Ler plants but to a significantly lesser extent in mutants agol-27 and dcll-9 (Fig. 3C and E). This result implied that AGO1 and DCL are required for AR156induced resistance to $P$. syringae pv. tomato.
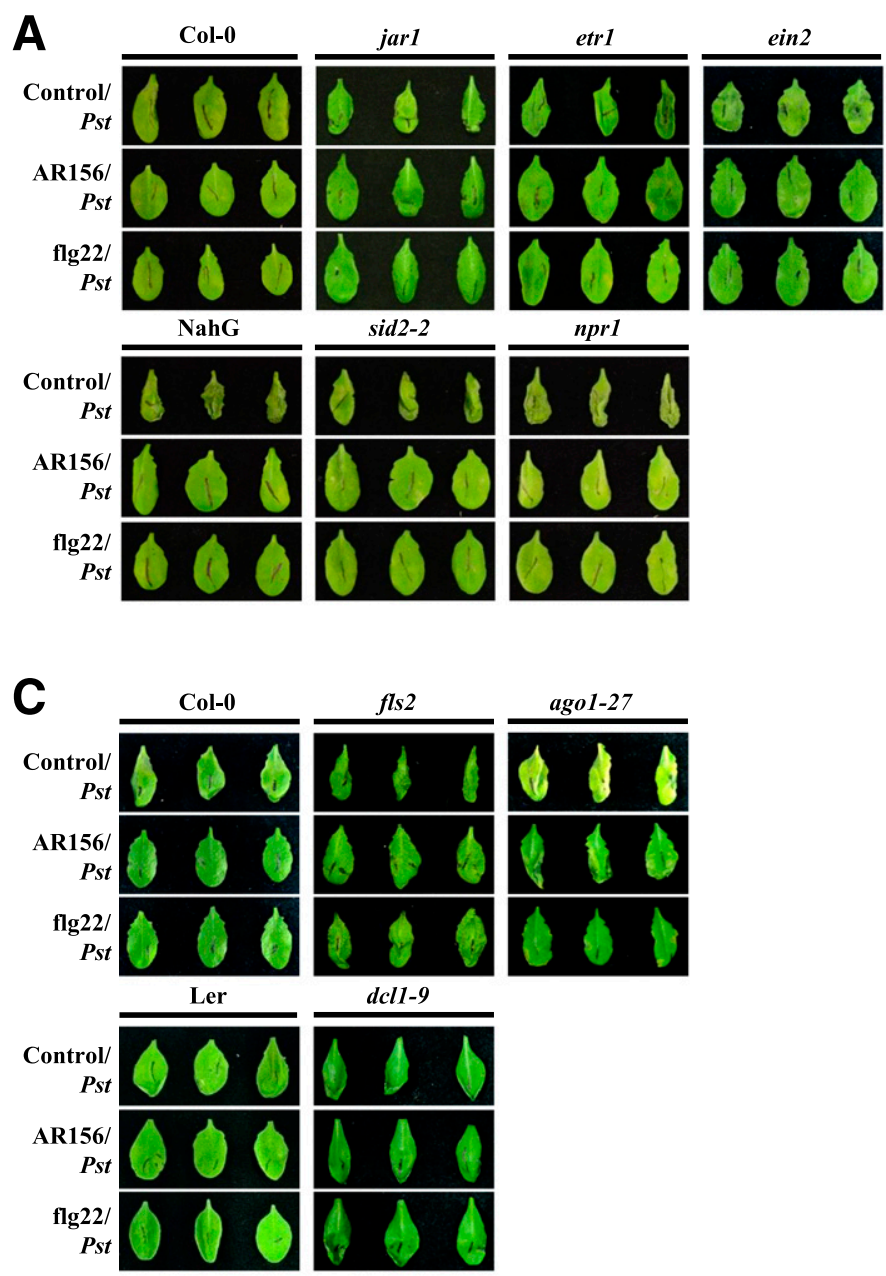

Fig. 3. AR156-induced resistance does not require salicylic acid (SA)-, jasmonic acid (JA)-, or ethylene (ET)-mediated pathways and FLS2 but involves AGO1 and DCL proteins. A and B, AR156- and flg22-induced resistance does not require SA, JA, and ET signaling pathways. Leaves of wild-type Col-0, NahG transgenic plants, and mutants (jarl, etrl, ein 2 , sid2-2, $n \mathrm{prl}$ ) were syringe-infiltrated with $5 \times 10^{7} \mathrm{CFU} / \mathrm{ml}$ AR156, $1 \mu \mathrm{M}$ flg 22 , or water for $24 \mathrm{~h}$ and were then infiltrated with Pseudomonas syringae pv. tomato $\left(5 \times 10^{5} \mathrm{CFU} / \mathrm{ml}\right)$. Images were taken and bacterial population densities in leaves were determined at 2 days postinoculation (dpi) with $P$. syringae pv. tomato $\left(5 \times 10^{5} \mathrm{CFU} / \mathrm{ml}\right)$. Two-way analysis of variance (ANOVA) with Tukey's test (significance set at $P<0.05$ ) was performed (Xin et al. 2016). The bacterial populations in control plants with different genotypes indicated by different lower-case letters (a versus b, c, and d) were significantly different (bc was not significantly different from $b$ or c), whereas differences in this parameter among different genotypes in AR156 and flg22 treatments are indicated by two sets of distinct lower-case letters ( $a^{\prime}$ versus $b^{\prime}, c^{\prime}$, and $d^{\prime}$ for AR156 treatment; and $a^{\prime \prime}$ versus $b^{\prime \prime}$ and c ${ }^{\prime \prime}$ for flg22 treatment); ns = not significant. The data presented are means \pm standard deviation (SD) $(n=12)$ from one representative experiment of the four independent repetitions. C, D, and E, Defects in flg22 sensing do not compromise AR156-triggered defense responses. AGO1 and DCL are required for both AR156- and flg22-induced resistance to $P$. syringae pv. tomato. FLS2 contributes to the resistance induced by flg22 but not to that by AR156. Leaves of Col-0, Ler, fls2, ago1-27, and dcll-9 were syringe-infiltrated with $5 \times 10^{7} \mathrm{CFU}$ of AR156 per milliliter, $1 \mu \mathrm{M}$ flg22, or water for $24 \mathrm{~h}$ and were then infiltrated with $P$. syringae pv. tomato $\left(5 \times 10^{5} \mathrm{CFU} / \mathrm{ml}\right)$. Images were taken and bacterial population densities in leaves were determined at $2 \mathrm{dpi}$ with $P$. syringae $\mathrm{pv}$. tomato $\left(5 \times 10^{5} \mathrm{CFU} / \mathrm{ml}\right)$. Twoway ANOVA was performed to compare the differences between AR156 and flg22 treatments in plants with different genotypes; ns, not significant. Asterisks (**) indicate significant differences at a $P$ value $<0.01$, respectively. The data presented are means $\pm \mathrm{SD}(n=12)$ from one representative experiment of the four independent repetitions. 
levels being downregulated in 35S::miR160a transgenic plants ( $\mathrm{Li}$ et al. 2010); miR167 targets ARF6 and ARF8 (Jones-Rhoades and Bartel 2004; Rhoades et al. 2002). miR398b targets CDS1 and CDS2 (Jones-Rhoades and Bartel 2004), as evidenced by their mRNA levels declining in $35 \mathrm{~S}:: m i R 398 \mathrm{~b}$ transgenic plants (Li et al. 2010). miR158a targets AT3G03580, miR169 targets AT1G17590 and AT5G12840, miR396 targets GRF3 (Li et al. 2010), and miR391 putatively targets GDS1. In addition to the genes targeted by the aforementioned miRNAs, MET2 is the target gene of miR773 (Fahlgren et al. 2007), whose expression was significantly up-regulated by flg 22 treatment, although the abundance of miR773 in plants was below the detection limit of RNA-blot assay (Li et al. 2010). As shown in Figure 4B, both treatments, AR156 and flg22, significantly repressed the expression of all target genes of six miRNAs (miR158a, miR160a, miR167, miR391, miR393, and miR396) relative to the control; conversely, the gene expression of CDS1, CDS2, and MET2 was consistently enhanced by both treatments. Expression of ATIG17590 and $A T 5 G 12840$, the genes targeted by miR169, was not significantly altered by flg 22 treatment in the work of other investigators ( $\mathrm{Li}$ et al. 2010); the same results were obtained in our study, but both genes showed reduced expression in response to AR156 (Fig. 4B). Taken together, the above results demonstrated that AR156 and flg22 differentially regulate the expression of miRNAs involved in PTI generally, in a similar manner, and that the expression of miRNAs is correlated with the expression of their putative target genes.

\section{AR156 and flg22 activated similar transcriptional programs.}

To further compare the function of AR156 and flg22 in triggering PTI responses to $P$. syringae pv. tomato, we identified the transcriptional programs regulated by AR156 and flg22 by comparing the genome-wide transcriptional changes in the two treatments. The leaves of 4-week-old wild-type Arabidopsis Col-0 plants were syringe-infiltrated with $1 \mu \mathrm{M}$ flg22, $5 \times 10^{7} \mathrm{CFU}$ of AR156 per milliliter, or water (the control) and were subjected to transcriptome analysis 1 day later. As a result, more than 17,000 genes were demonstrated to be differentially regulated by one or both AR156 and
A

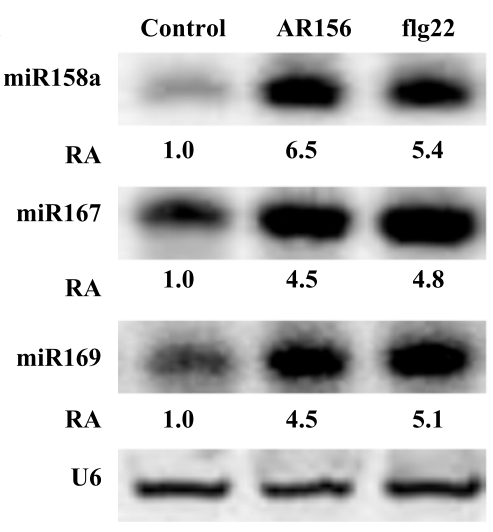

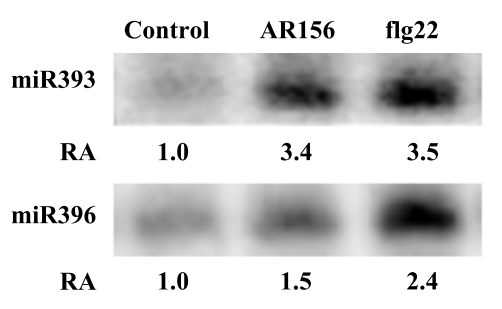

$\operatorname{miR398b}$

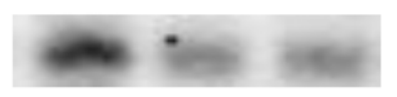

0.2

U6
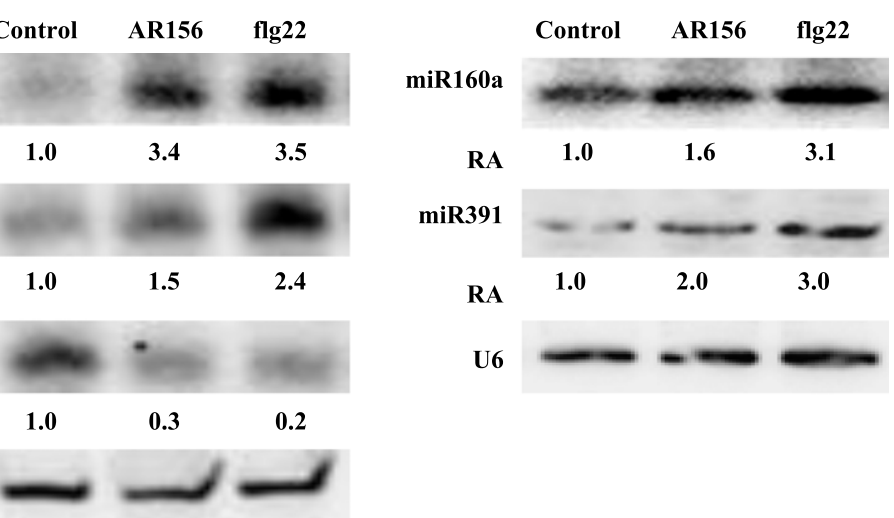

B
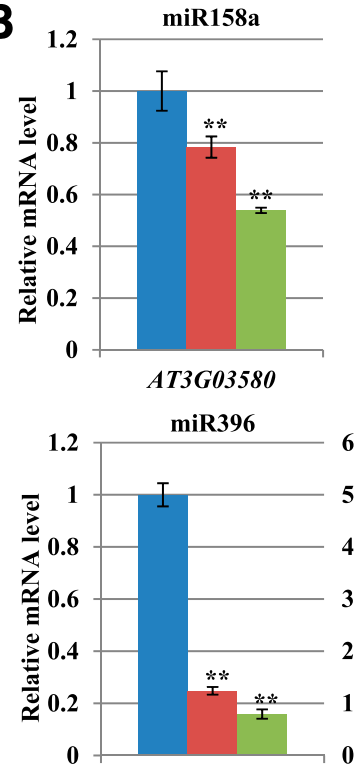

GRF3

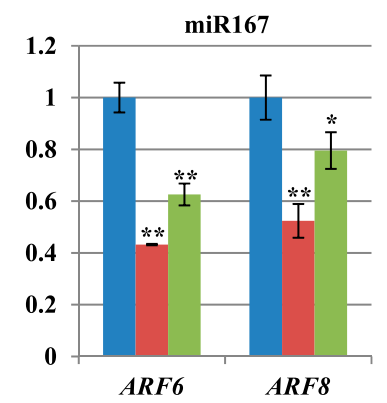

miR398b
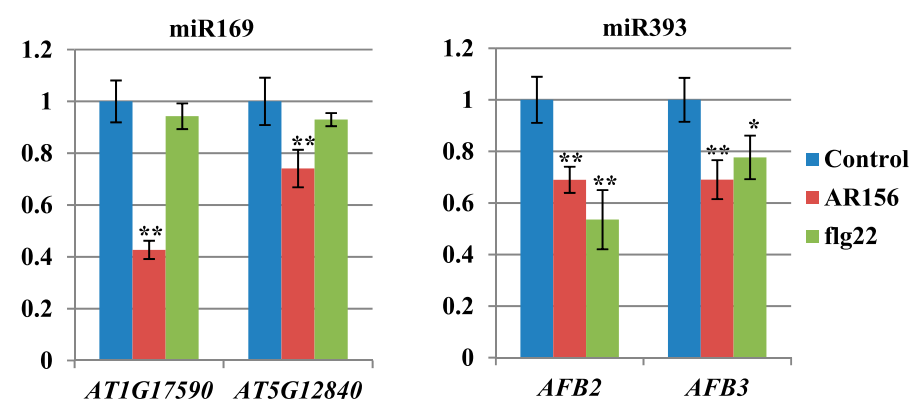

miR160a
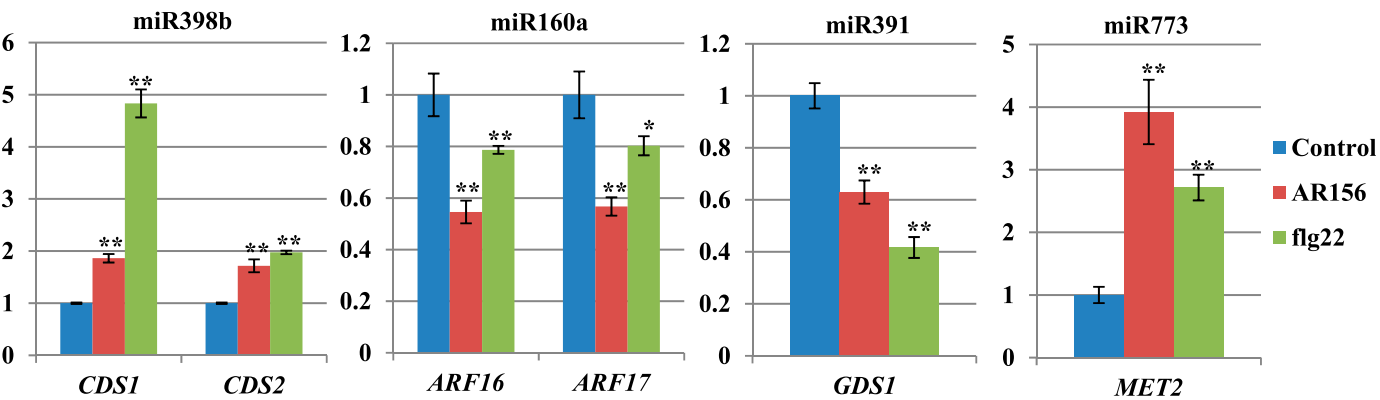

MET2

Fig. 4. Expression of selected microRNAs (miRNAs) and their target genes in response to treatments AR156 and flg22. A, Northern blotting analysis of miRNAs. Leaves of four-week-old Arabidopsis Col-0 plants were syringe-infiltrated with $5 \times 10^{7} \mathrm{CFU}$ of AR156 per milliliter, $1 \mu \mathrm{M}$ flg22, or water (the control) and were collected for RNA extraction at $24 \mathrm{~h}$ post-treatment (hpt). U6 was used as a loading control. B, Quantitative reverse transcription-polymerase chain reaction analysis of mRNA levels of genes targeted by miR158a (AT3G03580), miR160a (ARF16 and ARF17), miR167 (ARF6 and ARF8), miR169 (AT1G17590 and AT5G12840), miR391(GDS1), miR393 (AFB2 and AFB3), miR396 (GRF3), miR398b (CDS1 and CDS2), and miR773 (MET2). The data are shown as means \pm standard deviation from three technical replicates. Similar results were obtained in three biological replicates. Student's $t$ test was performed to determine the significance of the differences between treatment with AR156 or flg22 and the control. Asterisks (* and **) indicate significant differences at $P$ values $<0.05$ and $<0.01$, respectively. 
flg22 treatment (Supplementary Table S1). Genes with significant changes in expression levels in response to AR 156 or flg 22 treatment were determined according to a BenjaminiHochberg false discovery rate (FDR) $\leq 0.05$, with multipletesting correction, and a differentially expressed gene (DEG) was defined as having at least a twofold change $(\leq-1$ or $\geq 1$ in $\log _{2}$ ratio value) based on DESeq normalized read counts in response to treatment with AR156 or flg22. Consequently, a total of 1,302 DEGs were selected in AR156 and flg22 treatments (Supplementary Table S2), with 128 and 1,291 DEGs having altered expression levels in treatments with AR156 and flg22, respectively, relative to the control (Fig. 5A). A hierarchical heat-map image was generated to analyze these DEGs in response to different treatments (Fig. 5B). Of the 128 DEGs responsive to AR156, 117 were also responsive to flg22 (Fig. $5 \mathrm{~A}$ ), of which 111 were up-regulated by AR156 and six were down-regulated by it.

To understand the biological function of the 117 genes differentially regulated by both AR156 and flg22, the Kyoto Encyclopedia of Genes and Genomes (KEGG) Orthology database was used to identify the metabolic pathways involving them. Twenty of these genes were found to act in 15 pathways under three biologically functional categories: environmental information processing, metabolism processing, and organismal systems processing (Fig. 5C; Supplementary Table S3). Most of these pathways are associated with metabolism processing. Specifically, phenylpropanoid biosynthesis and phenylalanine metabolism pathways play an important role in plant immunity, since they are involved in the biosynthesis of significant secondary metabolites. On the other hand, amino sugar and nucleotide sugar metabolism, galactose metabolism, pentose and glucuronate interconversions, and starch and sucrose metabolism are related to the formation of plant cell walls (Lee et al. 2016).

The selected 1,302 DEGs regulated by one or both AR156 and flg22 were used to determine correlation coefficients between any two of the three treatments (AR156, flg22, and the control). AR156 and flg22 treatments induced highly correlated responses, indicated by the correlation coefficient of 0.76 (Fig. $5 \mathrm{D})$, despite the considerable difference in the number of DEGs between the two treatments (Fig. 5A). Notably, most of the DEGs were differentially regulated to a larger amplitude by treatment with $1 \mu \mathrm{M}$ flg22 than by treatment with AR156 at $5 \times 10^{7} \mathrm{CFU} / \mathrm{ml}$, in the transcriptome sequencing analysis (Fig. 5B). To verify the result of transcriptome sequencing, qRT-PCR was conducted to examine the expression of 16 DEGs coregulated by AR156 and flg22, of which ten were most strongly up-regulated by AR156 and six were down-regulated by it
A

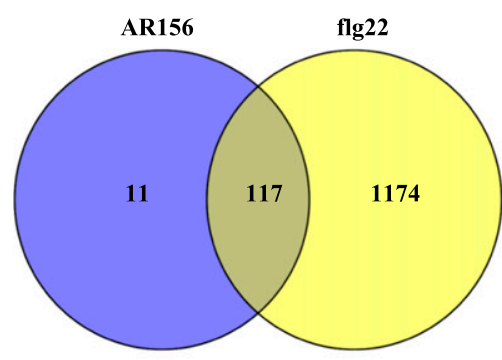

B

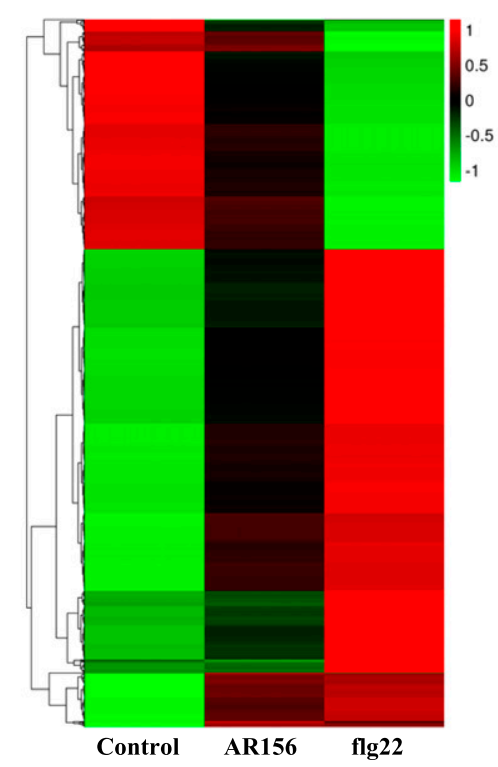

C Plant hormone signal transduction Cysteine and methionine metabolism Phenylalanine metabolism Phenylpropanoid biosynthesis Stilbenoid, diarylheptanoid and gingerol biosynthesis Amino sugar and nucleotide sugar metabolism Galactose metabolism Pentose and glucuronate interconversions Starch and sucrose metabolism Nitrogen metabolism Cyanoamino acid metabolism Glutathione metabolism Carotenoid biosynthesis Limonene and pinene degradation Plant-pathogen interaction

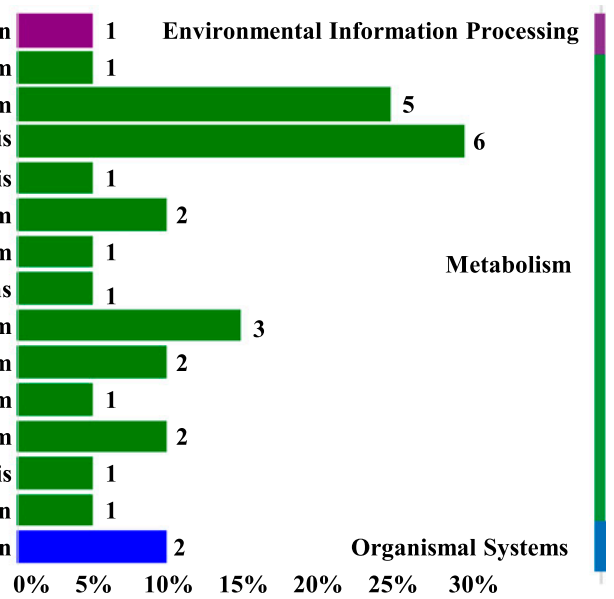

Correlation coefficients

\begin{tabular}{|c|c|c|c|}
\hline & Control & AR156 & flg22 \\
\hline Control & 1 & & \\
\hline AR156 & 0.45 & 1 & \\
\hline flg22 & 0.1 & 0.76 & 1 \\
\hline
\end{tabular}

Fig. 5. Transcript profiles of Arabidopsis Col-0 plants treated with AR156 or flg22. Leaves of four-week-old Arabidopsis Col-0 plants were syringe-infiltrated with AR156 at $5 \times 10^{7} \mathrm{CFU}$ of AR156 per milliliter, $1 \mu \mathrm{M}$ flg22, or water (the control). Samples were collected at 24 h post-treatment (hpt). A, Overlap between AR156- and flg22-mediated differentially expressed genes (DEGs) (false discovery rate of $\leq 0.05$ and $\log _{2}$ fold change $\geq|1|$ ). B, Hierarchical cluster analyses of expression levels of DEGs based on log ratio FPKM (fragments per kilobase of exon per million fragments mapped) data. The color key represents $(\mathrm{FPKM}+1)$ normalized $\log _{2}$ transformed counts. Red and green indicate high- and low-level gene expression, respectively. Each column represents a treatment, and each row represents a gene. C, The Kyoto Encyclopedia of Genes and Genomes (KEGG) Orthology database pathways involving the 117 DEGs coregulated by AR156 and flg22. D, DEGs correlation coefficients (Pearson correlation coefficient) between different treatments. 
(Table 1). Figure 6A and B show expression patterns in response to AR156 or flg22 relative to the control in the qRT-PCR analysis, which aligned with transcriptome sequencing data.

\section{DISCUSSION}

Bacillus cereus AR156 is a plant growth-promoting rhizobacterium that triggers both ISR and SAR in Arabidopsis against bacterial infection (Niu et al. 2011, 2016a). Our earlier study showed that pretreatment with AR156 suppressed the expression of miR398b and miR773 in wild-type Arabidopsis plants (Niu et al. 2016b), as did flg22. These two miRNAs negatively modulate PTI against bacterial pathogens ( $\mathrm{Li}$ et al. 2010). In this study, pretreatment of Arabidopsis Col-0 plants with AR156 or flg22 effectively inhibited $P$. syringae pv. tomato multiplication and also ameliorated the disease symptoms (Fig. 1), suggesting that AR156 behaves similarly to flg22 in activating immune responses, leading to reduced pathogen growth. Flg22 has been demonstrated to trigger PTI responses, such as activation of MAPK signaling, induction of hydrogen peroxide accumulation, callose deposition, and activation of defense-related gene expression (Asai et al. 2002; Gómez-Gómez et al. 1999), which all contribute to restriction of pathogen growth in plants (Nürnberger et al. 2004). In this study, we detected evident hydrogen peroxide accumulation, callose deposition, and PR1 expression in Arabidopsis Col-0 leaves infiltrated with AR156. Moreover, AR156, applied as foliar spray, led to phosphorylation of MPK3 and MPK6 and expression of early defense genes $F R K 1, W R K Y 22$, and WRKY29, as did flg22 (Fig. 2).

Table 1. Characteristics of 16 differentially expressed genes (DEGs) examined in the quantitative reverse transcription-polymerase chain reaction analysis

\begin{tabular}{|c|c|c|c|c|}
\hline \multirow[b]{2}{*}{ DEG ID } & \multirow[b]{2}{*}{ Primary sequence } & \multicolumn{2}{|c|}{$\log _{2}$ fold change } & \multirow[b]{2}{*}{ Function of DEGs } \\
\hline & & AR156 & flg22 & \\
\hline AT3G55150 & ATEXO7OH1 & 5.41351 & 6.65342 & $\begin{array}{l}\text { A member of the EXO70 gene family, } \\
\text { putative exocyst subunits, conserved in land } \\
\text { plants; Arabidopsis thaliana contains } 23 \\
\text { putative EXO70 genes, which can be } \\
\text { classified into eight clusters on the } \\
\text { phylogenetic tree }\end{array}$ \\
\hline AT1G44160 & $\cdots$ & 5.05182 & 7.06413 & $\begin{array}{l}\text { Encodes a HSP40/DnaJ peptide-binding } \\
\text { protein }\end{array}$ \\
\hline AT5G43290 & ATWRKY49 & 4.96243 & 5.9502 & $\begin{array}{l}\text { Encodes a WRKY transcription factor in } \\
\text { Group II-c }\end{array}$ \\
\hline$A T 1 G 18860$ & ATWRKY61 & 4.86998 & 5.64852 & $\begin{array}{l}\text { Encodes a WRKY transcription factor in } \\
\text { Group II-b }\end{array}$ \\
\hline AT5G39580 & $\ldots$ & 4.60275 & 6.15912 & $\begin{array}{l}\text { Encodes a peroxidase superfamily protein } \\
\text { functioning in peroxidase activity and heme } \\
\text { binding, involved in defense response to } \\
\text { fungus }\end{array}$ \\
\hline AT1G31885 & NIP3;1 & 4.49333 & 7.20497 & $\begin{array}{l}\text { Encodes a NOD26-like intrinsic protein } 3 ; 1 \\
\text { (NIP3;1) functioning in transporter activity, } \\
\text { involved in transport and transmembrane } \\
\text { transport }\end{array}$ \\
\hline AT1G68150 & ATWRKY9 & 4.49332 & 6.29881 & $\begin{array}{l}\text { Encodes a WRKY transcription factor in } \\
\text { Group II-b; its mRNA is cell-to-cell mobile }\end{array}$ \\
\hline AT1G69810 & ATWRKY36 & 4.41993 & 5.34704 & $\begin{array}{l}\text { Encodes a WRKY transcription factor in } \\
\text { Group II-b }\end{array}$ \\
\hline AT4G09770 & $\cdots$ & 4.23681 & 6.08637 & $\begin{array}{l}\text { Encodes a tumor necrosis factor receptor- } \\
\text { associated factor (TRAF)-like family } \\
\text { protein }\end{array}$ \\
\hline AT2G39530 & CASPLAD1 & 4.22446 & 6.80413 & Unknown \\
\hline AT3G09260 & $L E B$ & -3.8872 & -7.08336 & $\begin{array}{l}\text { Encodes } \beta \text {-glucosidase, the major constituent } \\
\text { of endoplasmic reticulum (ER) bodies and } \\
\text { one of the most abundant proteins in } \\
\text { Arabidopsis seedlings, which exists in } \\
\text { soluble (inactive) and insoluble (active) } \\
\text { form, most probably formed in a } \\
\text { polymerization process }\end{array}$ \\
\hline AT1G52040 & $M B P 1$ & -3.1418 & -4.93361 & $\begin{array}{l}\text { Encodes a myrosinase-binding protein } \\
\text { expressed in flowers }\end{array}$ \\
\hline AT2G10940 & $\cdots$ & -2.89134 & -7.11807 & $\begin{array}{l}\text { Encodes a bifunctional inhibitor/lipid- } \\
\text { transfer protein/seed storage } 2 \mathrm{~S} \text { albumin } \\
\text { superfamily protein, functioning in lipid } \\
\text { binding and involved in lipid transport }\end{array}$ \\
\hline AT3G28220 & $\cdots$ & -2.65761 & -3.13113 & $\begin{array}{l}\text { Encodes a TRAF-like family protein, } \\
\text { involved in response to salt stress and } \\
\text { located in vacuole and chloroplast envelope }\end{array}$ \\
\hline AT5G15780 & $\cdots$ & -2.55822 & -5.61531 & $\begin{array}{l}\text { Encodes a Pollen Ole e } 1 \text { allergen and } \\
\text { extensin family protein }\end{array}$ \\
\hline AT1G52400 & BGLU18 & -2.54111 & -4.34809 & $\begin{array}{l}\text { Encodes a member of glycosyl hydrolase } \\
\text { family } 1 \text {, located in inducible ER bodies } \\
\text { which are formed after wounding, required } \\
\text { for inducible ER body formation; its } \\
\text { mRNA is cell-to-cell mobile }\end{array}$ \\
\hline
\end{tabular}


It has been shown that flg22-induced resistance to $P$. syringae pv. tomato in Arabidopsis does not require SA, JA, and ET signaling (Zipfel et al. 2004). In line with this, pretreatment with AR156 still conferred resistance to $P$. syringae pv. tomato in NahG transgenic plants and in mutants jarl, etr1, ein2, sid2-2, and $n p r l$, indicating that SA, JA, and ET pathways are not indispensable to AR156-induced PTI responses. As demonstrated in previous studies, AR156 applied as a root drench primed Arabidopsis Col-0 plants for ISR to the biotrophic pathogen $P$. syringae pv. tomato, which is dependent on the SA and JA/ET signaling pathways as well as NPR1 (Niu et al. 2011), while JA and ET pathways and NPR1 are involved in ISR against $P$. syringae pv. tomato in Arabidopsis Col-0 triggered by the rhizobacterium $P$. fluorescens WCS417r applied as a root drench (Pieterse et al. 1998). In addition, another rhizobacterium, Pseudomonas putida WCS358r, conferred ISR in Arabidopsis but not in radish and carnation (Leeman et al. 1995; van Peer et al. 1991; Van Peer and Schippers 1992; Van Wees et al. 1997). In Arabidopsis Col-0 plants, rhizosphere colonization by AR156 elicited an ISR against the biotrophic pathogen $P$. syringae pv. tomato and an ISR against the necrotrophic pathogen Botrytis cinereal. However, different from the AR156-triggered ISR to $P$. syringae pv. tomato, the AR156-elicited ISR to $B$. cinerea does not require the SA signaling pathway (Nie et al. 2017). On the other hand, when infiltrated to leaves, AR156 induced SAR against $P$. syringae pv. tomato in Arabidopsis Col-0 plants by involving the SA signaling pathway and NPR1 (Niu et al. 2016a). Hence, we infer that the specificity of signaling pathway activation during induction of antibacterial resistance by elicitors depends on, not only the specific elicitor, host plant, and pathogen, but also, the specific method of applying an elicitor. Besides, AR156 still conferred disease resistance in $f l s 2$ mutants (Fig. 3C and D), suggesting that, unlike flg22, AR156 does not require FLS2, the receptor of flg22, for inducing PTI against $P$. syringae pv. tomato (Gómez-Gómez and Boller 2000; Zipfel et al. 2004). In our previous study (Niu et al. 2011), the unique MAMPs of AR156 are assumed to be recognized by several receptors of the plant, leading to generation of distinct signals. In this study, it is possible that AR156 induces the activation of the SA, JA, ET, and FLS2 signaling pathways in parallel and that knocking out a single pathway in the mutant alone does not abolish the induction of resistance. Future research is warranted to identify the receptor for AR156 in Arabidopsis.

Host endogenous sRNAs play an important regulatory role in reprogramming gene expression and contribute to plant defense responses (Katiyar-Agarwal and Jin 2010). Perception of flg22 induces the accumulation of miR393, the first identified miRNA that negatively regulates auxin signaling and contributes to the PTI by downregulation of TIR and $A F B$ transcripts (Navarro et al. 2006). Moreover, several other AGO1-bound miRNAs that are induced or repressed by flg 22 have also been identified as mediators of PTI. For example, flg22 induces the accumulation of miR160a, which positively regulates callose deposition by repressing the expression of its target genes ARF16 and $A R F 17$. By contrast, flg22 suppresses accumulation of miR398b and miR773, which negatively regulate callose deposition (Li et al. 2010). Here, we found that AR156 treatment induced accumulation of miR393 and miR160a while downregulating the expression of miR398b and miR773. It was reported that auxin treatment rendered Arabidopsis Col-0 plants more susceptible to biotrophic pathogens (Robert-Seilaniantz et al. 2011). Moreover, overexpression of miR393 led to the redirection of metabolic flow toward glucosinolates (GSs) and away from camalexin

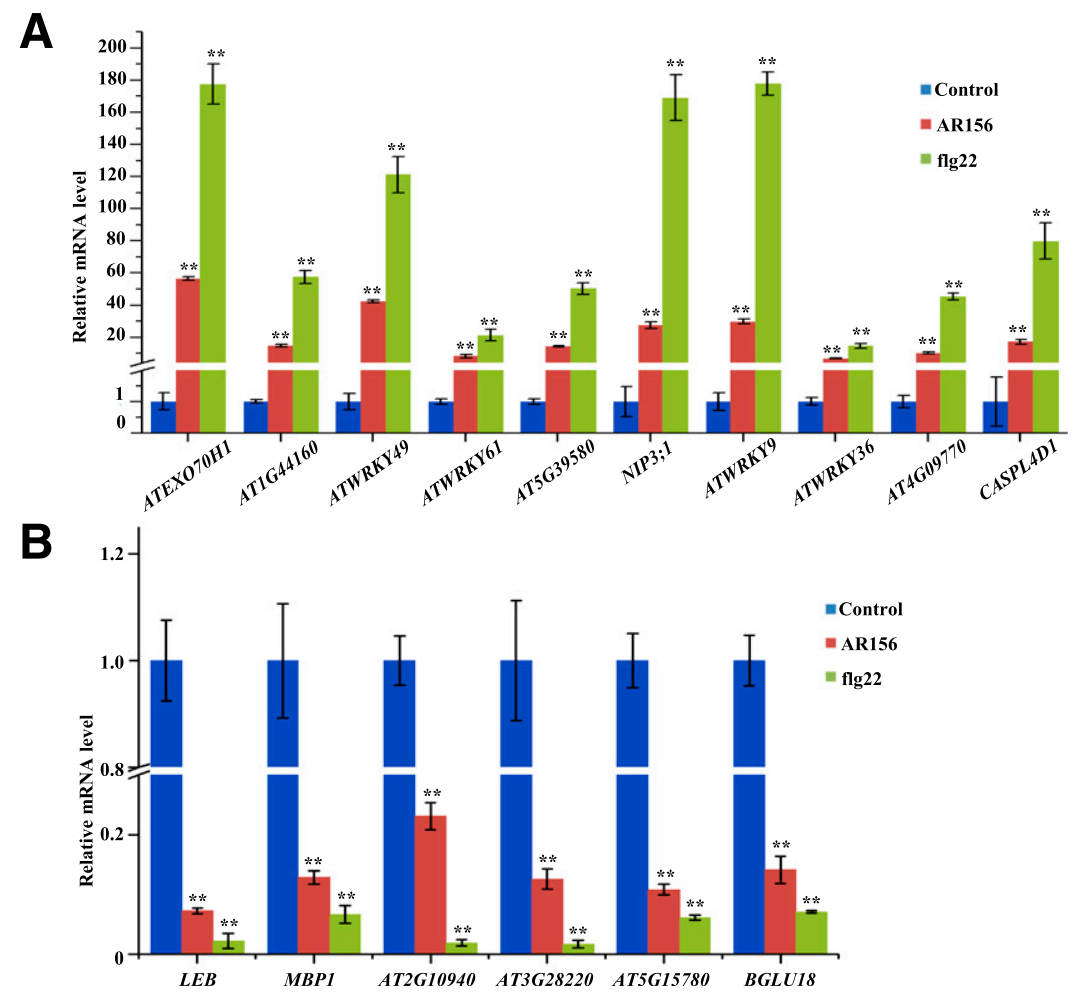

Fig. 6. Quantitative reverse transcription-polymerase chain reaction (qRT-PCR) analysis validating transcriptome sequencing results. Leaves of four-week-old Arabidopsis Col-0 plants were syringe-infiltrated with AR156 at $5 \times 10^{7} \mathrm{CFU} / \mathrm{ml}, 1 \mu \mathrm{M}$ flg22, or water (the control). Samples were collected at $24 \mathrm{~h}$ posttreatment (hpt). A, The transcript levels of 10 differentially expressed genes (DEGs) most strongly upregulated by AR156 treatment were determined by qRTPCR. B, The transcript levels of six DEGs downregulated by AR156 were determined by qRT-PCR. The data are shown as means \pm standard deviation from three technical replicates. Similar results were obtained in three biological replicates. Student's $t$ test was performed to determine the significance of the differences between treatment with AR156 or flg22 and the control. Asterisks (**) indicate significant differences at a $P$ value $<0.01$. 
(CL), which was the direct consequence of the suppression of auxin signaling (Robert-Seilaniantz et al. 2011), though both being antimicrobial molecules, GSs are toxic to a wide range of bacteria (Aires et al. 2009a and b) but CL does not contribute to bacterial defense (Nafisi et al. 2007). Taken together, AR156induced resistance to $P$. syringae pv. tomato might involve multiple signal pathways, including the auxin signaling and GS biosynthetic pathways.

To confirm the similarity between PTI responses to $P$. syringae pv. tomato induced by AR156 and flg22, we compared the full-genome transcriptional changes in Arabidopsis Col-0 leaves in treatments with AR156 and flg22. Of the 128 DEGs regulated by AR156, a vast majority (117) were also mediated by flg22. Also, the correlation coefficient calculated using DEGs between the two treatments was high (0.76). On the other hand, AR156 treatment differentially regulated a substantially lower number of genes and to a lesser amplitude than flg22 treatment (Figs. 5 and 6A and B). The 10 genes most highly up-regulated (by more than tenfold) by AR156 were identified as components of defense signaling pathways. Among them, AtEXO7OH1 is a member of the EXO7O gene family. Compared with wild-type Arabidopsis Col-0, the mutant atexo70H1 was more sensitive to Pseudomonas syringae pv. maculicola infection (Pečenková et al. 2011). AT5G39580 encodes a peroxidase, a key component of the plant ROS-generating system (Chen and Schopfer 1999). AT4G09770 encodes a tumor necrosis factor receptor-associated factor-like family protein, which plays important roles in plant development and response to abiotic stress (Bao et al. 2014). A member of the subfamily of nodulin 26-like intrinsic proteins (NIPs) of Arabidopsis, i.e., NIP3;1, encodes NIP3;1, which was demonstrated to extrude arsenite into the xylem for long-distance distribution by translocation from the root to the shoot in Arabidopsis (Xu et al. 2015); arsenite is a metalloid and highly toxic to a wide range of organisms including plants and humans (Abernathy et al. 2003; Tchounwou et al. 2004). Among the 10 DEGs most highly upregulated by AR156, four encode WRKY transcription factors, which exert regulatory function in plant defense response (Eulgem 2005); Arabidopsis plants overexpressing AtWRKY61 showed lower symptom severity and less virus accumulation upon Turnip crinkle virus attack compared with Arabidopsis Col-0 plants (Gao et al. 2016). Interestingly, the ten DEGs most highly upregulated by AR156 were also up-regulated by flg22, which elicited a greater amplitude of gene expression variation than AR156. Together, the above results indicate that the transcriptional changes triggered by AR156 overlap those elicited by flg 22 .

In this study, AR156 at $5 \times 10^{7} \mathrm{CFU} / \mathrm{ml}$ and flg22 at $1 \mu \mathrm{M}$ were similarly effective in protecting Arabidopsis Col-0 plants from $P$. syringae pv. tomato infection, as shown by the $P$. syringae pv. tomato population density and disease symptoms in leaves being reduced to a similar degree relative to the nontreated control (Fig. 1). This is inconsistent with the observation that, when compared with AR156 at $5 \times 10^{7} \mathrm{CFU} / \mathrm{ml}$, flg22 at $1 \mu \mathrm{M}$ triggered stronger PTI responses, including the abundance change of miRNAs involved in plant innate immunity and transcriptional changes. It could easily imagine a dose-dependent effect of AR156 or flg22 treatment on PTI responses that could produce the observed effects. However, if the AR156 dose was increased or the flg22 dose decreased, perhaps the PTI responses would be the same. While the effect of these doses on $P$. syringae pv. tomato growth is the same, there could be a threshold effect by which a base level of PTI induction is sufficient to control $P$. syringae pv. tomato growth or the lower P. syringae pv. tomato densities observed may be due in part to niche-occupation by AR156. Perhaps the PTI induced by AR156 coupled with the physical presence of the AR156 bacteria occupying the niche could combine to give the same effect as the flg22-induced PTI. Therefore, it would be worthwhile to identify the factors causing the discrepancy between the level of disease resistance and the extent of PTI responses triggered by AR156 relative to those elicited by flg22 in the future.

\section{MATERIALS AND METHODS}

Plant materials, bacterial strains, and growth conditions.

Arabidopsis plant lines used in this study were wild-type Columbia-0 (Col-0) and Landsberg erecta (Ler), transgenic line PR1::GUS, NahG (a transgenic line of Col-0 harboring the bacterial NahG gene) (Delaney et al. 1994), and mutants agol27, fls2, dcl1-9 (Ler background), sid2-2, jar1 (Staswick et al. 1992), etr1 (Bleecker et al. 1988), ein2 (Alonso et al. 1999), and nprl (Bowling et al. 1994). Plants were grown in a controlled growth room at $23 \pm 1{ }^{\circ} \mathrm{C}$ and with $70 \%$ relative humidity in a 12-h light and 12-h dark photoperiod.

Two-week-old Arabidopsis Col-0 seedlings grown on Murashige and Skoog medium were used for the MAPK activity assay and qRT-RCR analysis of PAMP-response genes FRK1, $W R K Y 22$, and WRKY29. Seedlings were collected at 0, 5, 15, and $30 \mathrm{~min}$ for the MAPK activity assay after treatment with AR156 or flg22, while seedlings were collected at $0,30,60$, 120, 240, and $360 \mathrm{~min}$ for the qRT-RCR analysis. Differently from the above experiments, 4-week-old soil-grown plants were consistently used for the other experiments in this study, as indicated below.

Bacillus cereus AR156 was grown in liquid Luria-Bertani medium at $28^{\circ} \mathrm{C}$ for $24 \mathrm{~h}$. Subsequently, bacterial cells were pelleted by centrifugation and were resuspended in sterile water for use. Pseudomonas syringae pv. tomato was grown in liquid King's B medium containing, per liter, $50 \mathrm{mg}$ of rifampicin and $50 \mathrm{mg}$ of kanamycin at $28^{\circ} \mathrm{C}$ overnight. Bacterial cells were pelleted by centrifugation and were resuspended in $10 \mathrm{mM} \mathrm{MgCl}_{2}$.

\section{Bacterial infection.}

Leaves of 4-week-old Arabidopsis plants were syringeinfiltrated with AR156 at $5 \times 10^{7} \mathrm{CFU} / \mathrm{ml}, 1 \mu \mathrm{M}$ flg22, or water (the control). One day after pretreatment, the leaves were challenge-inoculated by syringe-infiltration with a $P$. syringae pv. tomato suspension at the concentration of $5 \times 10^{5} \mathrm{CFU} / \mathrm{ml}$. Bacterial growth assays were performed as previously described, and at least 12 leaf discs were collected for each growth assay.

\section{qRT-PCR.}

Leaves of four-week-old Arabidopsis Col-0 plants were syringe-infiltrated with AR156 at $5 \times 10^{7} \mathrm{CFU} / \mathrm{ml}, 1 \mu \mathrm{M}$ flg22, or water (the control). Leaf tissues were sampled at $24 \mathrm{hpt}$, from which RNA was extracted using TRIzol reagent (Invitrogen, San Diego, CA, U.S.A.). Total RNA was treated with DNase I (Invitrogen). cDNA was synthesized from $1 \mu \mathrm{g}$ of RNA, using the SuperScript III first-strand synthesis system (Invitrogen). qRT-PCR was performed using SYBR Green JumpStart Taq ReadyMix (Sigma, St. Louis). The gene expression level was normalized using Actin2 as a control. Primers used in real-time PCR are shown in Supplementary Table S4.

\section{Detection of ROS burst and callose deposition.}

Leaves of 4-week-old Arabidopsis Col-0 plants were syringe-infiltrated with $1 \mu \mathrm{M}$ flg22, AR156 at $5 \times 10^{7} \mathrm{CFU} / \mathrm{ml}$, or water (the control). The leaves were collected at $24 \mathrm{~h}$ postinoculation and were then processed for detection of ROS burst and callose deposition according to previously described procedures (Niu et al. 2011). Briefly, to detect ROS burst, Arabidopsis leaves were stained with $1 \mathrm{mg}$ of diaminobenzidine 
(DAB) $(\mathrm{pH} 3.0)$ per milliliter, in the dark at room temperature for $8 \mathrm{~h}$. Subsequently, leaves were incubated in a solution of ethanol/acetic acid/glycerol $(3: 1: 1, \mathrm{vol} / \mathrm{vol} / \mathrm{vol})$ in a 90 to $95^{\circ} \mathrm{C}$ water bath for $20 \mathrm{~min}$ and were then gently rinsed with water before observation. DAB staining visualized hydrogen peroxide as red-brown precipitate under the light microscope. To determine callose deposition, leaves were immersed in $5 \mathrm{ml}$ of a destaining solution (phenol/glycerol/lactic acid/water/ethanol, $1: 1: 1: 1: 8$, $\mathrm{vol} / \mathrm{vol} / \mathrm{vol} / \mathrm{vol} / \mathrm{vol}$ ) in a bottle and were infiltrated by applying a vacuum for 5 to $10 \mathrm{~min}$. The bottle with samples was incubated in a $60^{\circ} \mathrm{C}$ water bath for 20 to $30 \mathrm{~min}$ to clear chlorophyll. The resultant chlorophyll-free leaves were gently rinsed with water and were then soaked in 3 to $5 \mathrm{ml}$ of a $0.01 \%$ (wt/vol) aniline blue staining solution containing $150 \mathrm{mM} \mathrm{K} \mathrm{HPO}_{4}(\mathrm{pH} 9.5)$ in the dark for 2 to $4 \mathrm{~h}$. After staining, leaves were gently rinsed with water and were then mounted on microscope slides for observation under an epifluorescence microscope equipped with a UV excitation filter.

\section{Histochemical GUS detection.}

Histochemical detection of GUS activity was conducted as previously described (Hua et al. 2001), with some modifications. Leaves of 4 -week-old transgenic $P R 1: \because G U S$ plants of Arabidopsis were syringe-infiltrated with AR156 at $5 \times 10^{7}$ $\mathrm{CFU} / \mathrm{ml}, 1 \mu \mathrm{M}$ flg22, or water (the control). Samples were collected at $24 \mathrm{hpt}$ and were then incubated in a staining solution (100 mM sodium phosphate, $\mathrm{pH} 7.0,10 \mathrm{mM}$ EDTA, $2 \mathrm{mM}$ 5-bromo-4-chloro-3-indoyl glucuronide, $1 \mathrm{mM}$ potassium ferricyanide, and $0.1 \%$ triton $\mathrm{X}-100$ ) at $37^{\circ} \mathrm{C}$ overnight. After incubation, stained leaf tissues were cleared of chlorophyll in an ethanol series.

\section{MAPK activity assay.}

Immunoblot detection of phosphorylated MPK3 and MPK6 was performed as previously described (Niu et al. 2016a). Twoweek-old seedlings grown on Murashige and Skoog medium were sprayed with $10 \mu \mathrm{M}$ flg 22 or AR156 at $5 \times 10^{8} \mathrm{CFU} / \mathrm{ml}$. Samples were collected at $0,5,10$, and $30 \mathrm{~min}$ and were analyzed by Western blotting using monoclonal rabbit phosphop44/42 MAPK (Erk1/2) (Thr202/Tyr204) (D13.14.4E) XP antibodies (Cell Signaling Technology, Danvers, MA, U.S.A.) (1:2,000 dilution). $\alpha$-Tubulin was used as a loading control and was detected with a monoclonal mouse anti- $\alpha$-tubulin (SigmaAldrich) (1:4,000 dilution)

\section{Transcriptome sequencing.}

Leaves of 4-week-old Arabidopsis Col-0 plants were syringe-infiltrated with AR156 at $5 \times 10^{7} \mathrm{CFU} / \mathrm{ml}, 1 \mu \mathrm{M}$ flg22, or water (the control). Samples were collected at $24 \mathrm{hpt}$. Total RNA was extracted from treated Arabidopsis Col-0 leaf tissues using TRIzol reagent (Invitrogen), following the manufacturer's instructions. Two biological replicates were used for each sample, and each sample contained tissues from at least ten whole plants.

For RNA-seq, the libraries were constructed and sequenced at Biomarker Technologies (Beijing, China) with an Illumina HiSeqX Ten platform. Paired-end reads from each sample were quality checked using FASTQC and were mapped to the Arabidopsis genome. RNA-seq data were normalized by FPKM (fragments per kilobase of exon per million fragments mapped). The Benjamini-Hochberg FDR threshold $\leq 0.05$ and a $\log _{2}$ fold change $\leq-1$ or $\geq 1$ based on DESeq normalized read counts were used as the criteria to determine differentially expressed genes.

Gene Ontologies were analyzed for term enrichment using the online tool released in the The Arabidopsis Information Resource website and DAVID bioinformatics resources. The
KEGG Orthology database was utilized for pathway mapping. We employed the MapMan package to visualize the metabolic pathways of the DEGs.

\section{RNA gel blot analysis.}

Leaves of 4-week-old Arabidopsis Col-0 plants were syringe-infiltrated with AR156 at $5 \times 10^{7} \mathrm{CFU} / \mathrm{ml}, 1 \mu \mathrm{M}$ flg22, or water (the control). Samples were collected at $24 \mathrm{hpt}$. Total RNA was isolated from treated leaves and was resolved on a $14 \%$ denaturing urea-polyacrylamide gel electrophoresis gel and was then transferred and ultraviolet-crosslinked onto a Hybond $\mathrm{N}^{+}$membrane (GE Healthcare Life Sciences, Piscataway, NJ, U.S.A.). miRNAs were detected using oligonucleotide probes, and miRNA probes were end-labeled with $\gamma$-32P-ATP using T4 polynucleotide kinase (New England Biolabs, Beverly, MA, U.S.A.). RNA gel blots were subsequently exposed on a phosphor imager screen.

\section{Statistical analysis.}

The specific statistical method used, the sample size, and the results of statistical analyses are described in the relevant figure legends. Statistical analysis was conducted using GraphPad Prism 6.0. Two-way ANOVA analysis with Tukey's test $(P<$ $0.05)$ was performed when treatments comprising different genotypes were compared. Different letters above the columns are used to indicate differences that are statistically significant. The Student's $t$ test was performed for comparison of means between two datapoints. Single and double asterisks above the columns indicate differences that are statistically significant $(P<0.05)$ or very significant $(P<0.01)$, respectively.

\section{ACKNOWLEDGMENTS}

This work was supported by the National Natural Science Foundation of China (31501621) and the Fundamental Research Funds for the Central Universities (Y0201700152) to D. D. Niu. We thank S. Yang (China Agricultural University) for kindly providing us with the seeds of Arabidopsis transgenic line PR1::GUS.

\section{LITERATURE CITED}

Abernathy, C. O., Thomas, D. J., and Calderon, R. L. 2003. Health effects and risk assessment of arsenic. J. Nutr. 133:1536S-1538S

Aires, A., Mota, V. R., Saavedra, M. J., Monteiro, A. A., Simões, M., Rosa, E. A. S., and Bennett, R. N. 2009a. Initial in vitro evaluations of the antibacterial activities of glucosinolate enzymatic hydrolysis products against plant pathogenic bacteria. J. Appl. Microbiol. 106:2096-2105.

Aires, A., Mota, V. R., Saavedra, M. J., Rosa, E. A. S., and Bennett, R. N. $2009 \mathrm{~b}$. The antimicrobial effects of glucosinolates and their respective enzymatic hydrolysis products on bacteria isolated from the human intestinal tract. J. Appl. Microbiol. 106:2086-2095.

Alonso, J. M., Hirayama, T., Roman, G., Nourizadeh, S., and Ecker, J. R. 1999. EIN2, a bifunctional transducer of ethylene and stress responses in Arabidopsis. Science 284:2148-2152.

Altenbach, D., and Robatzek, S. 2007. Pattern recognition receptors: From the cell surface to intracellular dynamics. Mol. Plant-Microbe Interact 20:1031-1039.

Asai, T., Tena, G., Plotnikova, J., Willmann, M. R., Chiu, W. L., GomezGomez, L., Boller, T., Ausubel, F. M., and Sheen, J. 2002. MAP kinase signalling cascade in Arabidopsis innate immunity. Nature 415:977-983.

Bao, Y., Wang, C., Jiang, C., Pan, J., Zhang, G., Liu, H., and Zhang, H. 2014. The tumor necrosis factor receptor-associated factor (TRAF)-like family protein SEVEN IN ABSENTIA 2 (SINA2) promotes drought tolerance in an ABA-dependent manner in Arabidopsis. New Phytol 202:174-187.

Bleecker, A. B., Estelle, M. A., Somerville, C., and Kende, H. 1988 Insensitivity to ethylene conferred by a dominant mutation in Arabidopsis thaliana. Science 241:1086-1089.

Bowling, S. A., Guo, A., Cao, H., Gordon, A. S., Klessig, D. F., and Dong, X. 1994. A mutation in Arabidopsis that leads to constitutive expression of systemic acquired resistance. Plant Cell 6:1845-1857. 
Brown, I., Trethowan, J., Kerry, M., Mansfield, J., and Bolwell, G. P. 1998. Localization of components of the oxidative cross-linking of glycoproteins and of callose synthesis in papillae formed during the interaction between non-pathogenic strains of Xanthomonas campestris and French bean mesophyll cells. Plant J. 15:333-343.

Chen, S. X., and Schopfer, P. 1999. Hydroxyl-radical production in physiological reactions. A novel function of peroxidase. Eur. J. Biochem. 260:726-735.

Chisholm, S. T., Coaker, G., Day, B., and Staskawicz, B. J. 2006. Hostmicrobe interactions: Shaping the evolution of the plant immune response. Cell 124:803-814.

Delaney, T. P., Uknes, S., Vernooij, B., Friedrich, L., Weymann, K., Negrotto, D., Gaffney, T., Gut-Rella, M., Kessmann, H., Ward, E., and Ryals, J. 1994. A central role of salicylic acid in plant disease resistance. Science 266:1247-1250.

Dow, M., Newman, M. A., and von Roepenack, E. 2000. The induction and modulation of plant defense responses by bacterial lipopolysaccharides. Annu. Rev. Phytopathol. 38:241-261.

Eulgem, T. 2005. Regulation of the Arabidopsis defense transcriptome. Trends Plant Sci. 10:71-78.

Fahlgren, N., Howell, M. D., Kasschau, K. D., Chapman, E. J., Sullivan, C. M., Cumbie, J. S., Givan, S. A., Law, T. F., Grant, S. R., Dangl, J. L., and Carrington, J. C. 2007. High-throughput sequencing of Arabidopsis microRNAs: Evidence for frequent birth and death of MIRNA genes. PLoS One 2:e219.

Felix, G., Duran, J. D., Volko, S., and Boller, T. 1999. Plants have a sensitive perception system for the most conserved domain of bacterial flagellin. Plant J. 18:265-276.

Gao, R., Liu, P., Yong, Y., and Wong, S. M. 2016. Genome-wide transcriptomic analysis reveals correlation between higher WRKY61 expression and reduced symptom severity in Turnip crinkle virus infected Arabidopsis thaliana. Sci. Rep. 6:24604.

Gómez-Gómez, L., Bauer, Z., and Boller, T. 2001. Both the extracellular leucine-rich repeat domain and the kinase activity of FSL2 are required for flagellin binding and signaling in Arabidopsis. Plant Cell 13:1155-1163.

Gómez-Gómez, L., and Boller, T. 2000. FLS2: An LRR receptor-like kinase involved in the perception of the bacterial elicitor flagellin in Arabidopsis. Mol. Cell 5:1003-1011.

Gómez-Gómez, L., Felix, G., and Boller, T. 1999. A single locus determines sensitivity to bacterial flagellin in Arabidopsis thaliana. Plant J. 18:277-284.

Gravino, M., Savatin, D. V., Macone, A., and De Lorenzo, G. 2015. Ethylene production in Botrytis cinerea- and oligogalacturonide-induced immunity requires calcium-dependent protein kinases. Plant J. 84:1073-1086.

Hua, J., Grisafi, P., Cheng, S. H., and Fink, G. R. 2001. Plant growth homeostasis is controlled by the Arabidopsis BON1 and BAP1 genes. Gene Dev. 15:2263-2272.

Jones, D. A., and Takemoto, D. 2004. Plant innate immunity-Direct and indirect recognition of general and specific pathogen-associated molecules. Curr. Opin. Immunol. 16:48-62.

Jones, J. D. G., and Dangl, J. L. 2006. The plant immune system. Nature 444:323-329.

Jones-Rhoades, M. W., and Bartel, D. P. 2004. Computational identification of plant microRNAs and their targets, including a stress-induced miRNA. Mol. Cell 14:787-799.

Kaku, H., Nishizawa, Y., Ishii-Minami, N., Akimoto-Tomiyama, C., Dohmae, N., Takio, K., Minami, E., and Shibuya, N. 2006. Plant cells recognize chitin fragments for defense signaling through a plasma membrane receptor. Proc. Natl. Acad. Sci. U.S.A. 103:11086-11091.

Katiyar-Agarwal, S., and Jin, H. 2010. Role of small RNAs in host-microbe interactions. Annu. Rev. Phytopathol. 48:225-246.

Kazan, K., and Manners, J. M. 2008. Jasmonate signaling: Toward an integrated view. Plant Physiol. 146:1459-1468.

Kim, M. G., da Cunha, L., McFall, A. J., Belkhadir, Y., DebRoy, S., Dangl, J. L., and Mackey, D. 2005. Two Pseudomonas syringae type III effectors inhibit RIN4-regulated basal defense in Arabidopsis. Cell 121:749-759.

Koornneef, A., and Pieterse, C. M. J. 2008. Cross talk in defense signaling. Plant Physiol. 146:839-844.

Lee, D. K., Ahn, S., Cho, H. Y., Yun, H. Y., Park, J. H., Lim, J., Lee, J., and Kwon, S. W. 2016. Metabolic response induced by parasitic plant-fungus interactions hinder amino sugar and nucleotide sugar metabolism in the host. Sci. Rep. 6:37434.

Leeman, M., Vanpelt, J. A., Denouden, F. M., Heinsbroek, M., Bakker, P. A. H. M., and Schippers, B. 1995. Induction of systemic resistance by Pseudomonas fluorescens in radish cultivars differing in susceptibility to fusarium wilt, using a novel bioassay. Eur. J. Plant Pathol. 101:655-664.

Li, F., Pignatta, D., Bendix, C., Brunkard, J. O., Cohn, M. M., Tung, J., Sun, H., Kumar, P., and Baker, B. 2012. MicroRNA regulation of plant innate immune receptors. Proc. Natl. Acad. Sci. U.S.A. 109:1790-1795.
Li, Y., Zhang, Q., Zhang, J., Wu, L., Qi, Y., and Zhou, J. M. 2010 Identification of microRNAs involved in pathogen-associated molecular pattern-triggered plant innate immunity. Plant Physiol. 152:2222-2231.

Mallory, A. C., Bartel, D. P., and Bartel, B. 2005. MicroRNA-directed regulation of Arabidopsis AUXIN RESPONSE FACTOR17 is essential for proper development and modulates expression of early auxin response genes. Plant Cell 17:1360-1375.

Nafisi, M., Goregaoker, S., Botanga, C. J., Glawischnig, E., Olsen, C. E., Halkier, B. A., and Glazebrook, J. 2007. Arabidopsis cytochrome P450 monooxygenase 71A13 catalyzes the conversion of indole-3-acetaldoxime in camalexin synthesis. Plant Cell 19:2039-2052.

Navarro, L., Dunoyer, P., Jay, F., Arnold, B., Dharmasiri, N., Estelle, M., Voinnet, O., and Jones, J. D. G. 2006. A plant miRNA contributes to antibacterial resistance by repressing auxin signaling. Science 312:436-439.

Nie, P., Li, X., Wang, S., Guo, J., Zhao, H., and Niu, D. 2017. Induced systemic resistance against Botrytis cinerea by Bacillus cereus AR156 through a JA/ET- and NPR1-dependent signaling pathway and activates PAMP-triggered immunity in Arabidopsis. Front. Plant Sci. 8:238.

Niu, D., Wang, X., Wang, Y., Song, X., Wang, J., Guo, J., and Zhao, H. 2016a. Bacillus cereus AR156 activates PAMP-triggered immunity and induces a systemic acquired resistance through a NPRI-and SAdependent signaling pathway. Biochem. Biophys. Res. Commun. 469: $120-125$.

Niu, D., Wang, Z., Wang, S., Qiao, L., and Zhao, H. 2015. Profiling of small RNAs involved in plant-pathogen interactions. Pages 61-79 in: Plant Gene Silencing. Methods and Protocols, Springer, New York.

Niu, D., Xia, J., Jiang, C., Qi, B., Ling, X., Lin, S., Zhang, W., Guo, J., Jin, H., and Zhao, H. 2016b. Bacillus cereus AR156 primes induced systemic resistance by suppressing miR825/825* and activating defense-related genes in Arabidopsis. J. Integr. Plant Biol. 58:426-439.

Niu, D. D., Liu, H. X., Jiang, C. H., Wang, Y. P., Wang, Q. Y., Jin, H. L., and Guo, J. H. 2011. The plant growth-promoting rhizobacterium Bacillus cereus AR156 induces systemic resistance in Arabidopsis thaliana by simultaneously activating salicylate- and jasmonate/ethylene-dependent signaling pathways. Mol. Plant-Microbe Interact 24:533-542.

Nürnberger, T., Brunner, F., Kemmerling, B., and Piater, L. 2004. Innate immunity in plants and animals: Striking similarities and obvious differences. Immunol. Rev. 198:249-266.

Pečenková, T., Hála, M., Kulich, I., Kocourková, D., Drdová, E., Fendrych, M., Toupalová, H., and Zársky, V. 2011. The role for the exocyst complex subunits Exo70B2 and Exo70H1 in the plant-pathogen interaction. J. Exp. Bot. 62:2107-2116.

Pieterse, C. M. J., Van der Does, D., Zamioudis, C., Leon-Reyes, A., and Van Wees, S. C. M. 2012. Hormonal modulation of plant immunity. Annu. Rev. Cell Dev. Biol. 28:489-521.

Pieterse, C. M. J., van Wees, S. C. M., van Pelt, J. A., Knoester, M., Laan, R., Gerrits, H., Weisbeek, P. J., and van Loon, L. C. 1998. A novel signaling pathway controlling induced systemic resistance in Arabidopsis. Plant Cell 10:1571-1580.

Rhoades, M. W., Reinhart, B. J., Lim, L. P., Burge, C. B., Bartel, B., and Bartel, D. P. 2002. Prediction of plant microRNA targets. Cell 110: 513-520.

Robert-Seilaniantz, A., MacLean, D., Jikumaru, Y., Hill, L., Yamaguchi, S., Kamiya, Y., and Jones, J. D. G. 2011. The microRNA miR393 re-directs secondary metabolite biosynthesis away from camalexin and towards glucosinolates. Plant J. 67:218-231.

Staswick, P. E., Su, W., and Howell, S. H. 1992. Methyl jasmonate inhibition of root growth and induction of a leaf protein are decreased in an Arabidopsis thaliana mutant. Proc. Natl. Acad. Sci. U.S.A. 89: 6837-6840.

Sun, Y., Li, L., Macho, A. P., Han, Z., Hu, Z., Zipfel, C., Zhou, J. M., and Chai, J. 2013. Structural basis for flg22-induced activation of the Arabidopsis FLS2-BAK1 immune complex. Science 342:624-628.

Tchounwou, P. B., Centeno, J. A., and Patlolla, A. K. 2004. Arsenic toxicity, mutagenesis, and carcinogenesis-a health risk assessment and management approach. Mol. Cell. Biochem. 255:47-55.

Thomma, B. P. H. J., Nürnberger, T., and Joosten, M. H. A. J. 2011. Of PAMPs and effectors: The blurred PTI-ETI dichotomy. Plant Cell 23:4-15.

Van Wees, S. C. M., Pieterse, C. M. J., Trijssenaar, A., Van't Westende, Y. A. M., Hartog, F., and Van Loon, L. C. 1997. Differential induction of systemic resistance in Arabidopsis by biocontrol bacteria. Mol. PlantMicrobe Interact 10:716-724.

van Peer, R., Niemann, G. J., and Schippers, B. 1991. Induced resistance and phytoalexin accumulation in biological control of fusarium wilt of carnation by Pseudomonas sp strain Wcs417r. Phytopathology 81:728-734.

Van Peer, R., and Schippers, B. 1992. Lipopolysaccharides of plant-growth promoting Pseudomonas sp strain $\mathrm{Wcs} 417 \mathrm{r}$ induce resistance in carnation to fusarium wilt. Neth. J. Plant Pathol. 98:129-139. 
Xin, X. F., Nomura, K., Aung, K., Velásquez, A. C., Yao, J., Boutrot, F., Chang, J. H., Zipfel, C., and He, S. Y. 2016. Bacteria establish an aqueous living space in plants crucial for virulence. Nature 539:524529.

Xu, W., Dai, W., Yan, H., Li, S., Shen, H., Chen, Y., Xu, H., Sun, Y., He, Z., and Ma, M. 2015. Arabidopsis NIP3;1 plays an important role in arsenic uptake and root-to-shoot translocation under arsenite stress conditions. Mol. Plant 8:722-733.

Yi, S. Y., Shirasu, K., Moon, J. S., Lee, S. G., and Kwon, S. Y. 2014. The activated SA and JA signaling pathways have an influence on flg22triggered oxidative burst and callose deposition. PLoS One 9:e88951.

Zhai, J., Jeong, D. H., De Paoli, E., Park, S., Rosen, B. D., Li, Y., González, A. J., Yan, Z., Kitto, S. L., Grusak, M. A., Jackson, S. A., Stacey, G., Cook, D. R., Green, P. J., Sherrier, D. J., and Meyers, B. C. 2011. MicroRNAs as master regulators of the plant $N B-L R R$ defense gene family via the production of phased, trans-acting siRNAs. Genes Dev. 25:2540-2553.

Zhang, X., Zhao, H., Gao, S., Wang, W. C., Katiyar-Agarwal, S., Huang, H. D., Raikhel, N., and Jin, H. 2011. Arabidopsis Argonaute 2 regulates innate immunity via miRNA393*-mediated silencing of a Golgi-localized SNARE gene, MEMB12. Mol. Cell 42:356-366.

Zipfel, C., and Felix, G. 2005. Plants and animals: A different taste for microbes? Curr. Opin. Plant Biol. 8:353-360.

Zipfel, C., Robatzek, S., Navarro, L., Oakeley, E. J., Jones, J. D. G., Felix, G., and Boller, T. 2004. Bacterial disease resistance in Arabidopsis through flagellin perception. Nature 428:764-767.

\section{AUTHOR-RECOMMENDED INTERNET RESOURCES}

The Arabidopsis Information Resource website: http://www.arabidopsis.org

DAVID bioinformatics resources: http://david.abcc.ncifcrf.gov FastQC: http://www.bioinformatics.babraham.ac.uk/projects/fastqc GraphPad Prism 6.0 software: https://www.graphpad.com The Kyoto Encyclopedia of Genes and Genomes (KEGG) Orthology database: http://www.genome.jp/kegg/ko.html

The MapMan package: http://MapMan.gabipd.org 